\title{
Modern treatment of acromegaly
}

\section{Z Merza}

Postgrad Med J 2003;79:189-194

Acromegaly is an endocrine disorder characterised by increased morbidity and mortality. It is usually caused by a growth hormone secreting pituitary adenoma and is manifested by a variety of clinical features. Surgery is usually the treatment of choice, however over the last few years, several new methods of treatment have been developed. A recent consensus on the targets for treatment has led to multiple studies being conducted to assess the efficacy of the currently available options. This review examines the evidence for and against these treatments.

Correspondence to: Dr Zayd Merza, Endocrine and Diabetes Centre,

Northern General Hospital, Sheffield S5 7AU, UK zmerza@aol.com

Submitted

27 November 2002

Accepted

21 December 2002
A cromegaly is a clinical condition that results from chronic secretion of abnormally high amounts of growth hormone after fusion of the epiphyseal plates leading to an increased production of insulin-like growth factor-1 (IGF-1). It is usually caused by a growth hormone secreting anterior pituitary adenoma. Forty percent of patients carry a mutation in the $\alpha$-subunit of the Gs protein coupled with the growth hormonereleasing hormone $(\mathrm{GHRH})$ receptor $(g s p+v e) .{ }^{1} \mathrm{It}$ affects 40-60 people per million with an annual incidence of 3-4 per million. ${ }^{2}$ It is associated with increased morbidity and mortality with mortality being 2-3 times that of an age and sex matched normal population. This is due to an increased risk of cancer, cardiovascular and respiratory disease. ${ }^{3}$ Acromegaly is characterised by multiple signs and symptoms; common features include enlargement of bones and soft tissues, hyperhydrosis, lethargy, arthralgia, and headaches and in severe cases visual field defects. On average patients present around the age of 45 years with $75 \%$ of them having a macroadenoma at the time of diagnosis. ${ }^{1}$ Pierre Marie first defined it as a syndrome in 1885 and in 1909 Harvey Cushing performed his first operation for acromegaly. ${ }^{25}$ Since then several new methods of treatment have been developed but transsphenoidal surgery remains the primary treatment of choice. In the last few years a number of new medical treatments have been introduced with promising results such as long acting somatostatin analogues and growth hormone receptor antagonists.

Various targets for treatment have been used in the past but the current consensus is to aim for a nadir growth hormone level of less than $1 \mu \mathrm{g} / \mathrm{l}$ after an oral glucose tolerance test and a normal IGF- 1 level for age and sex. ${ }^{6}$ There is also a general agreement that a basal growth hormone level below $2.5 \mu \mathrm{g} / \mathrm{l}$ is an acceptable target to consider the patient cured. This is mainly based on the results of several studies, which have shown that the mortality rate of patients with acromegaly is similar to that of the general population when growth hormone levels below this level are achieved. $^{3}{ }^{4}$

\section{SURGICAL THERAPY}

Surgery is the first line treatment for most patients with acromegaly. Transsphenoidal selective adenomectomy is the procedure of choice. On rare occasions craniotomy may be needed when suprasellar extension prevents the transsphenoidal approach. The cure rate of surgery is about $80 \%$ for microadenomas and $40 \%$ for macroadenomas with a recurrence rate of about $5 \%-10 \% .^{7-9}$ Tumour size and preoperative growth hormone levels play an important part in determining the out come of surgery.

In a study by Kreutzer et al 57 acromegalic patients were analysed retrospectively using the new criteria for disease control. ${ }^{5}$ All patients included had transsphenoidal surgery as their primary treatment; the short term remission rate was $48.8 \%$ at six weeks increasing to $66.7 \%$ after 12 months or more (mean 37.7 months). Tumour size was significantly greater in patients with persistent or resistant acromegaly. Patients with mixed growth hormone/prolactin cells and mammosomatotroph adenomas had the lowest remission rate. In another study 59 patients who had transsphenoidal surgery by one neurosurgeon were followed up for at least 10 years (10-22 years), using a random growth hormone level below $2.5 \mu \mathrm{g} / \mathrm{l}$ as a remission criterion; 61\% achieved early postoperative remission. This was closely related to preoperative serum growth hormone levels. Forty percent of patients remained in remission after a mean of 16 years. ${ }^{10}$ Swearingen et al followed up 149 patients for a mean of 7.8 years after transsphenoidal surgery; the cure rate was $91 \%$ for microadenomas and $48 \%$ for macroadenomas. ${ }^{8}$ There was a $6 \%$ and $10 \%$ recurrence rate after 10 and 15 years respectively compared with $5.4 \%$ after a mean of 5.4 years in a different study involving 115 patients. ${ }^{9}$

Kaltsas et al found that tumour size, the degree of hypopituitarism, growth hormone and prolactin levels but not IGF-1 levels were useful factors in predicting the outcome of surgery. ${ }^{11}$ In addition, the mean growth hormone levels were more reliable indicators of surgical outcome and disease activity when compared with random growth hormone and/or IGF- levels.

The effect of preoperative octreotide has been assessed in a number of studies with variable

Abbreviations: $\mathrm{GHRH}$, growth hormone-releasing hormone; GKS, gamma knife radiosurgery; IGF-1 insulin-like growth factor- 1 


\section{Box 1: Surgical therapy}

- Treatment of choice for most patients.

- Cure rates about $80 \%$ and $40 \%$ for microadenoms and macroadenomas respectively.

- Transsphenoidal selective adenomectomy is the procedure of choice.

- Outcome is highly dependent on the skills and experience of the neurosurgeon.

- Safe with low morbidity and mortality

results, some suggesting a beneficial role while others showed no significant difference. ${ }^{12-14}$ In one study comparing 90 patients who had received preoperative octreotide to 50 who had not, no significant difference was detected and no transformation of a non-resectable adenoma to a transsphenoidally resectable adenoma was observed. ${ }^{15}$

The experience and skills of the neurosurgeon are especially important in determining the outcome of surgery. ${ }^{16}{ }^{17}$ A study comparing the cure rates between surgery performed by one of eight different surgeons and that of a single dedicated surgeon, showed that the cure rate increased from 33\% to $64 \%$. The cure rate being $86 \%$ and $52 \%$ for microadenomas and macroadenomas respectively in case of the latter. ${ }^{16}$ Various results have been obtained from patients who have undergone a second operation for persistent or recurrent acromegaly after previous transsphenoidal surgery, with success being as low as $19 \%$ (three out of 16) in one study and as high as 73\% (eight out of 11) in another. ${ }^{818}$ Transsphenoidal surgery for acromegaly is generally safe with low morbidity and very low mortality rate. Complications affect less than 3.5\% of cases and include transient or permanent diabetes insipidus, syndrome of inappropriate antidiuretic hormone secretion, haemorrhage, and cerebrospinal fluid leak. Surgical hypopituitarism is rare with microadenomas but affects $5 \%-10 \%$ of patients with macroadenomas. ${ }^{5}$

\section{MEDICAL THERAPY}

\section{Dopamine agonists}

Dopamine agonists such as bromocriptine and cabergoline have been used with limited effect in the treatment of acromegaly. In one study three different dopamine agonists were assessed: quiangolide, cabergoline, and long acting depot bromocriptine. Thirty four patients were divided into three groups and followed up for 6-12 months. After six months only five out of 16 in the quinagolide group had a normal IGF- 1 level and a growth hormone less than $2 \mu \mathrm{g} / \mathrm{l}$ after an oral glucose tolerance test. None of the patients in the other two groups achieved these results, although all patients reported a significant improvement in their symptoms. A significant association was found between positive growth hormone plus prolactin immunostaining and response to treatment. ${ }^{19}$ Cabergoline, a long acting dopamine agonist was assessed in a multicentre study involving 64 patients; 16 of whom had a growth hormone/prolactin cosecreting tumour and 22 had received no previous form of therapy. IGF-1 levels below 300 $\mu \mathrm{g} / \mathrm{l}$ were achieved in $39 \%$ and between $300-450 \mu \mathrm{g} / \mathrm{l}$ in $67 \%$ of cases. A better response was observed in cosecreting adenomas and when pre-treatment IGF-1 levels were below 750 $\mu \mathrm{g} / \mathrm{l}$. Treatment was well tolerated with gastrointestinal symptoms and postural hypotension at the start of treatment being the main side effects. Tumour shrinkage was observed in 13 out of 21 patients and was more marked in growth hormone/ prolactin cosecreting adenomas. ${ }^{20}$

There has been evidence that combined treatment of cabergoline and lanreotide can be effective in selected cases resistant to somatostatin analogues alone. ${ }^{21}$ In addition, the oral route of dopamine agonist administration and its low cost are two main advantages when compared to somatostatin analogues.

\section{Somatostatin analogues}

Growth hormone secretion from the pituitary gland is normally regulated by the stimulatory effect of GHRH and inhibitory effect of somatostatin, plus a feedback mechanism from IGF-1. Growth hormone secretion by tumour cells in acromegaly usually retains a high sensitivity to the inhibitory effect of somatostatin. Most tumours contain a large number of high affinity somatostatin receptors, which are diffusely distributed over the adenoma. ${ }^{22}$ Five subtypes of the human somatostatin receptor have been cloned. Subtype 2 is related to the antimitotic effect of somatostatin in some cells, and the inhibition of cell proliferation is mediated by subtype $5 .^{23}$ This forms the basis for using octreotide and lanreotide, which are long acting somatostatin analogues and bind with high affinity to these 2 subtypes of the receptor. Octreotide was the first medical treatment for acromegaly to be effective in a large proportion of patients. However because of the high doses needed and the fact that it is administered three times daily subcutaneously it is less convenient for the patients. It has now been replaced with sustained release forms of somatostatin analogues such as octreotide LAR and lanreotide SR. Lanreotide SR is usually given in a fixed dose of $30 \mathrm{mg}$ intramuscularly every seven, 10, or 14 days while octreotide LAR is given intramuscularly every 28 days in a 10,20 , or $30 \mathrm{mg}$ dose. Several studies have assessed the efficacy and tolerability of these two drugs, with success rates ranging from $45 \%-65 \%$. The main adverse effects of somatostatin analogues are diarrhoea, nausea, abdominal pain, and pain at the injection site. Gallstones, usually asymptomatic and detected by ultrasonography, develop in 3\%-12\% of patients. ${ }^{24}{ }^{25}$ This variability might be related to environmental, racial, and dietary factors. The development of gallstones is most likely due to the inhibition of both gall bladder emptying and cholecystokinin secretion. ${ }^{23}$ Tumour shrinkage occurs in $13 \%-36 \%$ of cases. $^{242627}$

Starting with lanreotide SR, in a multicentre study involving 66 patients with active acromegaly all of whom apart from three had received at least one form of treatment in the past, $45 \%$ achieved a growth hormone level below $2.5 \mu \mathrm{g} / \mathrm{l}$ and $44 \%$ a normal IGF-1 level on lanreotide $30 \mathrm{mg}$ intramuscularly. Tumour shrinkage of at least $25 \%$ was achieved in five out of 14 patients and symptoms improved by more than $50 \%{ }^{24}$ In a similar study involving 58 patients, most of whom had undergone pituitary surgery in the past, lanreotide PR was given for 12 months. At the end of one, six, and 12 months of treatment plasma growth hormone levels below $2.5 \mu \mathrm{g} / \mathrm{l}$ were achieved in $22 \%, 33 \%$, and $41 \%$ respectively. ${ }^{25}$

In a two year follow up study by Baldelli et al, 118 patients were treated with lanreotide SR, 23 were de novo patients. ${ }^{27}$ The de novo patients showed a better response rate than the previously irradiated or operated on patients with fasting growth hormone levels below $7.5 \mu \mathrm{g} / \mathrm{l}$ and normal IGF-1 levels achieved in $78 \%$ and $70 \%$ of them respectively. This may simply be due to the de novo group containing patients with tumours more sensitive to lanreotide, or radiotherapy and surgery may result in changes rendering the tumour less responsive. On the other hand a follow up study of 31 patients treated with radiotherapy showed that patients on octreotide at the time of irradiation achieved normal levels of growth hormone and IGF-1 at a much longer interval than patients not on octreotide suggesting a radioprotective effect of somatostatin analogues. ${ }^{28}$

The effect of somatostatin analogues on the control of diabetes mellitus has been variable, ranging from improvement to worsening of control. ${ }^{24-26}$ Since they inhibit insulin secretion, deterioration in diabetes control might be expected, however its ability to delay the absorption of carbohydrates and inhibit the secretion of growth hormone and glucagon may prevent any significant effect on carbohydrate metabolism. ${ }^{23}$ There has been evidence that increasing the 
dose of lanreotide SR to $60 \mathrm{mg}$ from $30 \mathrm{mg}$ results in a significant reduction in tumour size. ${ }^{29}$ Lanreotide SR has also been used in the treatment of a patient with a GHRH secreting carcinoid tumour with significant improvement in symptoms and growth hormone levels. ${ }^{30} \mathrm{~A}$ new long acting formulation of lanreotide (Lanreotide Autogel) has been assessed in the management of 107 patients with acromegaly previously responsive to lanreotide $30 \mathrm{mg}$ intramuscularly. This new formula is administrated by a deep subcutaneous injection every 28 days. Thirty nine percent of patients on the subcutaneous formula compared with $33 \%$ on the imtramuscular formula achieved growth hormone levels below $2.5 \mu \mathrm{g} / \mathrm{l}$ and normal IGF-1. The control of symptoms was comparable between the two treatments. ${ }^{31}$

Octreotide LAR, the second main sustained release somatostatin analogue, was assessed in a European multicentre study which involved 151 patients who received 10,20 , or $30 \mathrm{mg}$ intramuscularly at four week intervals and were followed up for 12 months. About $70 \%$ of patients achieved suppression of mean growth hormone levels below $2.5 \mu \mathrm{g} / \mathrm{l}$. There was no increase in gallstone formation and it was very well tolerated with no adverse effect related withdrawals. There was a significant improvement in symptoms after the sixth injection. ${ }^{32}$ Similar results were achieved by a smaller study involving 14 patients followed up for 18 months. ${ }^{33}$ KendallTaylor et al compared the effect of octreotide LAR with lanreotide SR on five patients. ${ }^{34}$ They were treated with each medication for six months with a wash out period in between. Four patients achieved growth hormone levels below $2.5 \mu \mathrm{g} / \mathrm{l}$ with each drug. Patients found octreotide LAR injections less painful and caused less diarrhoea. A growth hormone nadir of less than $1 \mu \mathrm{g} / \mathrm{l}$ in four patients was achieved only with octreotide LAR. Costwise the two drugs are comparable.

Some authors have suggested that somatostatin analogues may be used as a first line therapy. Newman et al compared 26 de novo patients with 81 patients whom had undergone surgery and/or radiotherapy in the past. ${ }^{35}$ Both groups were started on octreotide and followed up for a mean of 24 months. There was no significant difference between the two groups with growth hormone levels falling at least 2 SD below the base line in $70 \%$ and $61 \%$ of patients respectively. This is supported by the results of Baldelli et al mentioned above. ${ }^{27}$ Bevan et al have recently shown that somatostatin analogues can be effective as primary treatment in normalising growth hormone/IGF-1 and inducing tumour shrinkage especially in patients with a pre-treatment growth hormone level below 20 $\mu \mathrm{g} / \mathrm{l}^{36}$

\section{Growth hormone receptor antagonist}

B2036-PEG (pegvisomant) is a genetically engineered analogue of human growth hormone that acts as a growth hormone receptor antagonist. It is a new form of treatment with promising efficacy in the management of acromegaly. The growth hormone molecule has two binding sites by which it binds to two identical cell surface receptor molecules, causing dimerisation and receptor activation leading to intracellular signalling and IGF-1 production. ${ }^{37}$ Pegvisomant is characterised by two mutations, at site 1 which increases its affinity to one receptor molecule and at site 2 which blocks its binding to a second molecule, preventing dimerisation and IGF-1 production. ${ }^{38} \mathrm{~B} 2036$ is conjugated to polyethylene glycol; this increases its half life and reduces its immunogenicity but also reduces its affinity to the growth hormone receptor. Therefore levels much higher than endogenous growth hormone concentrations are needed to block the receptors. ${ }^{39}$ A study by Ross et al has suggested that B2036 does cause dimerisation and induce internalisation but not intracellular signalling. ${ }^{40}$

Two trials have shown that pegvisomant is highly effective in treating acromegaly. The first was a randomised, double blind, placebo controlled trial involving 112 patients whom
Box 2: Medical therapy

Dopamine agonists

- Mainly effective in tumours with positive growth hormone plus prolactin immunostaining.

- Oral route of administration and low cost.

- Less effective compared with other treatments.

\section{Somatostatin analogues}

- Success rate about $45 \%-65 \%$.

- Can be effective as a first line therapy.

- Parenteral route of administration.

- Tumour shrinkage occurs in about $30 \%$ of cases.

Growth hormone receptor antagonist

- Genetically engineered analogue of human growth hormone molecule.

- $97 \%$ of patients achieve normal IGF-1 levels.

- Growth hormone levels remain high.

Not yet available for commercial use.

were divided into three groups receiving a daily dose of 10,15 , or $20 \mathrm{mg}$ subcutaneously plus the placebo group and followed up for 12 weeks. Eighty one percent of patients on $15 \mathrm{mg}$ and $89 \%$ of patients on $20 \mathrm{mg}$ achieved normal levels of IGF-1 with significant improvement of their symptoms..$^{38}$ In a larger and longer study to assess the long term efficacy of pegvisomant, 160 patients were treated for an average of 425 days. Ninety seven percent of patients treated for 12 months achieved normal IGF-1 levels. The drug was well tolerated; however, two patients had serious derangement of their liver enzyme levels which gradually settled after withdrawing the drug. ${ }^{41}$ Pegvisomant has also been successful in treating patients who are resistant to somatostatin analogues and dopamine agonists. ${ }^{42}{ }^{43}$ None of these studies showed a significant effect of pegvisomant on the tumour size, although there was a very mild increase in patients who had not received radiotherapy in the past. In one particular patient who had proved difficult to control with various modes of treatment, there was progression in his tumour size when started on pegvisomant. However, at a later stage when treated with a combination of octreotide and pegvisomant his visual field defect resolved with no further increase in the tumour size after four months. ${ }^{44}$

Growth hormone level has been recognised as the main determinant of mortality in acromegalic patients and it is strongly recommended that it should be normalised as part of the treatment. ${ }^{6}$ This cannot be achieved in patients on pegvisomant as growth hormone levels increase, mainly due to the feedback effect from blocking its receptors, preventing it from being used a marker for disease control in such patients.

\section{RADIOTHERAPY}

\section{Conventional radiotherapy}

Pituitary radiotherapy has been used for many years in the treatment of acromegaly. With the introduction of pituitary microsurgery and new medical treatments, it is now mainly used as an adjuvant treatment and in patients unsuitable or refusing surgery. It is delivered in fractionated doses over five weeks with a total radiation dose of 4500-5000 cGy. Its main two disadvantages are the prolonged delay in achieving target growth hormone levels, sometimes up to 20 years, and the high incidence of hypopituitarism. However, further tumour growth is prevented in more than $99 \%$ of cases..$^{45}$ In a study by Barrande et al, 128 patients ( 104 had undergone transsphenoidal surgery in the past) were followed up for a mean of 11.5 years after receiving conventional radiotherapy in a single centre. ${ }^{46}$ Basal growth hormone levels below $2.5 \mu \mathrm{g} / \mathrm{l}$ were achieved in $7 \%$ and $66 \%$ of patients after two and 15 years respectively. Pre-radiation growth hormone levels were the 


\section{Box 3: Radiotherapy}

\section{Conventional radiotherapy}

- Prolonged delay in achieving target growth hormone levels.

- High incidence of hypopituitarism.

- Tumour growth is prevented in more than $99 \%$ of cases

\section{Stereotactic radiosurgery}

- Delivered in a single session.

- Especially useful for tumours invading the cavernous sinus.

- Contraindicated in suprasellar tumour extension.

sole factor predicting a delay in response. The prevalence of hypopituitarism increased progressively with time; 10 years after treatment gonadotropic, thyrotrophic, and corticotropic deficiencies were observed in $80 \%, 78 \%$, and $82 \%$ of patients respectively. Some studies have shown lower success rates $(16 \%-34 \%)$ in patients followed up for 10 years or more. ${ }^{47}{ }^{48}$ In a study by Cozzi et al, 149 patients were followed up for a median of 14 years after conventional radiotherapy. ${ }^{49}$ Normal IGF-1 and growth hormone levels below $2.5 \mu \mathrm{g} / \mathrm{l}$ were achieved in only $16 \%$ and $12 \%$ of patients respectively. Patients who had not been maintained on either a somatostatin analogues or dopamine agonists during the time of irradiation achieved the best results. This supports the findings mentioned above by Landolt et al. ${ }^{28}$

Rare late complications after radiotherapy include damage to the optic nerves and chiasm, seizures, and radionecrosis of brain tissue. There is also evidence of an increased risk of a second brain tumour, neuropsychological effects, and possible cerebrovascular disease. ${ }^{50-53}$

\section{Stereotactic radiosurgery}

Gamma knife radiosurgery (GKS) is a modern form of radiotherapy. It is delivered in a single session from a cobalt-60 source by focused radiation with little radiation to the surrounding brain tissue, both advantages compared with conventional radiotherapy. It is especially useful for tumours invading the cavernous sinuses where the cranial nerves are much less susceptible to damage from radiation than the optic nerves. However it is contraindicated in cases of suprasellar extension due to the risk of optic nerve or chiasm damage..$^{54}$ In one study, 68 patients treated by GKS (most of whom as primary treatment), were followed up for 6-52 months. Normalisation of growth hormone was achieved in $40 \%$ of patients followed up for 12 months and $96 \%$ of patients followed up for more than 24 months. The tumour size shrank in 52\% and $87 \%$ of cases respectively. ${ }^{55}$ In another study comparing GKS with conventional fractionated radiotherapy in patients who have had unsuccessful surgery in the past, the mean time for simultaneous normalisation of growth hormone $(<5 \mu \mathrm{g} / \mathrm{l})$ and IGF-1 was 1.4 years for the GKS group compared with 7.1 years for the fractionated radiotherapy group. ${ }^{56}$ Longer follow up studies are needed to assess the long term efficacy and adverse effects of GKS

\section{CONCLUSION}

Acromegaly is a serious disease characterised by increased morbidity and mortality. Several forms of treatment are available and with the introduction of new criteria for cure, multiple studies have been conducted to review the efficacy of these treatment modalities. Despite the development of new drugs in the last few years and the use of GKS, transsphenoidal surgery remains the primary treatment of choice for most patients. The importance of a dedicated and skilled neurosurgeon cannot be understated. However medical and radiotherapy still have an important role in the treatment of acromegaly especially in patients who are resistant to, refuse, or have recurrence after surgery. The main drawbacks of

\section{Box 4: Key references}

- Bates AS, Van't Hoff W, Jones JM, et al. An audit of outcome of treatment in acromegaly. Q J Med 1993;86:293-9.

- Giustina A, Barkan A, Casanueva F, et al. Criteria for cure of acromegaly: a consensus statement. J Clin Endocrinol Metab 2000;85:526-9.

- Kreutzer J, Vance ML, Lopes BS, et al. Surgical management of $\mathrm{GH}$-secreting pituitary adenomas: an outcome study using modern remission criteria. J Clin Endocrinol Metab 2001;86:4072-7.

- Lancranjan I, Athinson AB. Results of a European multicentre study with Sandostatin LAR in acromegalic patients. Sandostatin LAR group. Pituitary 1999;1:105-14.

- Van der Lely AJ, Hutson RK, Trainer PJ, et al. Long-term treatment of acromegaly with pegvisomant, a growth hormone receptor antagonist. Lancet 2001;358:1754-9.

radiotherapy are the long interval between treatment and cure and the high incidence of hypopituitarism. New medical treatments have shown promising results with even some suggestions to consider long acting somatostatin analogues as a first line option. Pegvisomant, which is not yet available for commercial use, has shown very good response rates. However because it blocks the actions of growth hormone rather than addresses the source of the problem, it is less favourable as a primary choice. There is also some concern about the possibility of tumour enlargement during long term therapy especially in patients who have not received radiotherapy in the past. Dopamine agonists, although less effective, are especially useful in patients with growth hormone/prolactin cosecreting adenomas, knowing that these patients have low response rates to surgery. Tumour size and growth hormone levels are important factors in predicting the outcome of treatment. As patients usually present with a macroadenoma at the time of diagnosis, most will need more than one form of treatment to achieve safe levels of growth hormone and symptom control.

\section{SELF ASSESSMENT QUESTIONS (TRUE (T)/FALSE (F); ANSWERS AT END OF REFERENCES)}

Q1. Acromegaly:

(A) Results from abnormally high serum levels of growth hormone before fusion of the epiphyseal plates.

(B) $90 \%$ of patients carry the ( $g s p+v e)$ mutation.

(C) Hyperhydrosis and arthralgia are common features.

(D) Patients usually present in the fifth decade of life.

(E) $75 \%$ of patients present with a microadenoma.

Q2. Surgical therapy for acromegaly:

(A) Transsphenoidal selective adenomectomy is the procedure of choice.

(B) The cure rate is about $80 \%$ for macroadenomas.

(C) Preoperative growth hormone level is an important indicator of the outcome of surgery.

(D) Hypopituitarism is common after surgery.

(E) Complications include diabetes insipidus and syndrome of inappropriate antidiuretic hormone secretion.

Q3. Medical therapy for acromegaly:

(A) Dopamine agonists are effective in growth hormone/ prolactin cosecreting adenomas.

(B) Dopamine agonists are administered subcutaneously.

(C) Somatostatin analogues are the drugs of choice for most patients. 
(D) Pegvisoment normalises growth hormone levels in the majority of patients.

(E) Pegvisoment is a growth hormone receptor agonist.

Q4. Somatostatin analogues:

(A) Are successful in $45 \%-65 \%$ of patients.

(B) Asymptomatic gallstones develop in 30\% of patients.

(C) Octreotide LAR is administered intramuscularly every 28 days.

(D) Can be successful as a first line therapy.

(E) Are available in intramuscular and subcutaneous formulas.

Q5. Radiotherapy:

(A) Conventional radiotherapy is applied over several weeks.

(B) Normal growth hormone levels are usually achieved within six months of conventional radiotherapy.

(C) Hypopituitarism is an uncommon complication.

(D) GKS has shown promising results.

(E) GKS is especially useful for tumours invading the optic chiasm.

\section{REFERENCES}

1 Faglia G. Clinical aspects of the anterior pituitary gland. In: Pinchera A, ed. Endocrinology and metabolism. New York: McGraw-Hill, 2001: 73-98.

2 Holdaway M, Rajasoorya C. Epidemiology of acromegaly. Pituitary 1999;2:29-41

3 Bates AS, Van't Hoff W, Jones JM, et al. An audit of outcome of treatment in acromegaly. QJ Med 1993;86:293-9.

4 Orme SM, Mcnally RJ, Cartwright RA, et al. Mortality and cancer incidence in acromegaly: a retrospective cohort study. United Kingdom Acromegaly Study Group. Clin Endocrinol Metab 1998;83:2730-4.

5 Kreutzer J, Vance ML, Lopes BS, et al. Surgical management of $\mathrm{GH}$-secreting pituitary adenomas: an outcome study using modern remission criteria. J Clin Endocrinol Metab 2001;86:4072-7.

6 Giustina A, Barkan A, Casanueva F, et al. Criteria for cure of acromegaly: a consensus statement. J Clin Endocrinol Metab 2000:85:526-9.

7 Aron DC, Findling JW, Tyrrell JB. Hypothalamus and pituitary. In: Greenspan FS, Gardner DG, eds. Basic \& clinical endocrinology. 6th Ed. New York: Lange/McGraw-Hill, 2001: 100-62.

8 Swearingen B, Barker IIF, Katznelson L, et al. Long-term mortality after transsphenoidal surgery and adjunct therapy for acromegaly. J Clin Endocrinol Metab 1998:83:3419-26.

9 Freda PU, Wardlaw SL, Post KD. Long-term endocrinological follow-up evaluation in 115 patients who underwent transsphenoidal surgery for acromegaly. J Neurosurg 1998;89:353-8.

10 Biermasz N, Van Dulken H, Roelfsema F. Ten year follow up results of transsphenoidal microsurgery in acromegaly. J Clin Endocrinol Metab 2000:85:4596-602.

11 Kaltsas GA, Isidori AM, Florakis D, et al. Predictors of the outcome of surgical treatment in acromegaly and the value of the mean growth hormone day curve in assessing postoperative disease activity. J Clin Endocrinol Metab 2001;86:1645-51.

12 Stevenaert A, Beckers A. Presurgical octreotide treatment in acromegaly. Metabolism 1996:45(8 suppl 1):72-4.

13 Stevenaert A Harris A Kovacs K, et al. Presurgical octreotide treatment in acromegaly. Metabolism 1992;41(9 suppl 2):51-8.

14 Biermasz NR, Van Dulken H, Roelfsema F. Direct post operative and follow up results of transsphenoidal surgery in 19 acromegalic patients treated with octreotide compared to those in untreated matched controls. J Clin Endocrinol Metab 1999:84:3551-5.

15 Takumi A, Ludecke K. Effects preoperative octreotide treatment on different subtypes of $90 \mathrm{GH}$-secreting pituitary adenomas and outcome in one surgical centre. Eur J Endocrinol 2001;145:137-45.

16 Gittoes NJ, Sheppard MC, Johnson AP, et al. Outcome of surgery for acromegaly-the experience of a dedicated pituitary surgeon. $Q J$ Med 1999;92:741-5.

17 Lisset CA, Peacy SR, Laing I, et al. The outcome of surgery for acromegaly: the need for a specialist pituitary surgeon for all types of $\mathrm{GH}$ secreting adenomas. Clin Endocrinol (Oxf) 1998;49:653-7.

18 Long $\mathbf{H}$, Somma M, Comtois R, et al. Surgical outcome after repeated transsphenoidal surgery in acromegaly. J Neurosurg 1996;85:239-47.

19 Colao A, Ferone D, Marzullo P, et al. Effects of different dopaminergic agents in the treatment of acromegaly. J Clin Endocrinol Metab 1997:82:518-23.

20 Abs R, Verhelst J, Maiter D, et al. Cabergoline in the treatment of acromegaly: a study in 64 patients. J Clin Endocrinol Metab 1998;83:374-8.
21 Marzullo P, Ferone D, Di Somma C, et al. Efficacy of combined treatment with lanreotide and cabergoline in selected therapy-resistant acromegalic patients. Pituitary 1999;1:115-20.

22 Lamberts SWJ. Acromegaly. In: Grossman A, ed. Clinical endocrinology. 2nd Ed. Oxford: Blackwell Science, 1998: 170-83.

23 Lamberts SWJ, VanderLely AJ, deHerder WW, et al. Octreotide. N Engl J Med 1996;334:246-53.

24 Verhelst J, Pedroncelli AM, Abs R, et al. Slow-release lanreotide in the treatment of acromegaly: a study in 66 patients. Eur J Endocrinol 2000:143:577-84

25 Chanson $\mathbf{P}$, Leselbaum A, Blumberg J, et al. Efficacy and tolerability of long-acting somatostatin analogue lanreotide in acromegaly. A 12-month multicentre study of 58 acromegalic patients. Pituitary 2000;2:269-76.

26 Caron PH, Morange-Ramos I, Cogne M, et al. Three year follow up of acromegalic patients treated with intramuscular slow-release lanreotide. $J$ Clin Endocrinol Metab 1997;82:18-22.

27 Baldelli R, Colao N, Razzore P, et al. Two-year follow-up of acromegalic patients treated with slow release lanreotide $(30 \mathrm{mg})$. J Clin Endocrinol Metab 2000:85:4099-103.

28 Landolt A, Haller D, Lomax N, et al. Octreotide may act as a radioprotective agent in acromegaly. J Clin Endocrinol Metab 2000;85: 1287-9

29 Cozzi R, Barausse M, Sberna M, et al. Lanreotide $60 \mathrm{mg}$, a longer acting somatostatin analog: tumour shrinkage and hormonal normalisation in acromegaly. Pituitary $2001 ; 3: 231-8$

30 Drange M, Melmed S. Long-acting lanreotide induces clinical and biochemical remission of acromegaly caused by disseminated growth hormone-releasing-hormone secreting carcinoid. J Clin Endocrinol Metab 1998;83:3104-9.

31 Caron PH, Bekers A, Cullen DR, et al. Efficacy of the new long-acting formulation of lanreotide (lanreotide autogel) in the management of acromegaly. J Clin Endocrinol Metab 2002;87:99-104.

32 Lancranjan I, Athinson $A B$. Results of a European multicentre study with Sandostatin LAR in acromegalic patients. Sandostatin LAR group. Pituitary $1999 \cdot 1: 105-14$

33 Flogstad AK, Halse J, Bakke $S$, et al. Sandostatin LAR in acromegalic patients: long term treatment. J Clin Endocrinol Metab 1997;82:23-8

34 Kendall-Taylor P, Miller M, Gebbie J, et al. Long-acting octreotide LAR compared with lanreotide SR in the treatment of acromegaly. Pituitary 2000;3:61-5.

35 Newman C, Melmed S, George A, et al. Octreotide as primary therapy for acromegaly. J Clin Endocrinol Metab 1998;83:3034-40.

36 Bevan JS, Atkin SL, Atkinson AB, et al. Primary medical therapy for acromegaly: an open, prospective, multicentre study of the effects of subcutaneous and intramuscular slow-release octreotide on growth hormone, insulin-like growth factor-I, and tumour size. J Clin Endocrinol Metab 2002;87:4554-63.

37 Fuh G, Cunningham BC, Fukunaga $R$, et al. Rational design of potent antagonist to the human growth hormone receptor. Science 1992;256:1677-80.

38 Trainer $\mathbf{P}$, Drake WM, William M, et al. Treatment of acromegaly with growth hormone receptor antagonist pegvisomant. N Engl J Med 2000;342:1171

39 Drake WM, Parkinson C, Besser GM, et al. Clinical use of growth hormone receptor antagonist in the treatment of acromegaly. Trends Endocrinol Metab 2001:12:408-13.

40 Ross RJM, Leung KC, Maamra M, et al. Binding and functional studies with growth hormone receptor antagonist, B2036-PEG (pegvisomant), reveal effects of pegylation and evidence that it binds to a receptor dimer. J Clin Endocrinol Metab 2001;86:1716-23.

41 Van der Lely AJ, Hutson RK, Trainer PJ, et al. Long-term treatment of acromegaly with pegvisomant, a growth hormone receptor antagonist. Lancet 2001;358:1754-9.

42 Drake WM, Parkinson C, Akker SA, et al. Successful treatment of resistant acromegaly with growth hormone receptor antagonist. Eur Endocrinol 2001:145:451-6.

43 Herman-Bonert VS, Zib K, Scarlett JA, et al. Growth hormone receptor antagonist therapy in acromegalic patients resistant to somatostatin analogs. J Clin Endocrinol Metab 2000;85:2958-61.

44 Van der Lely AJ, Muller AF, Janssen JA, et al. Control of tumour size and disease activity during cotreatment of octreotide and the growth hormone receptor antagonist pegvisomant in an acromegalic patient. $J$ Clin Endocrinol Metab 2001;86:478-81.

45 Eastman RC, Gorden P, Glatstein E, et al. Radiation therapy of acromegaly. Endocrinol Metab Clin North Am 1992;21:693-712.

46 Barrande G, Pittino-Lungo M, Coste J, et al. Hormonal and metabolic effects of radiotherapy in acromegaly: long-term results in 128 patients followed in a single centre. J Clin Endocrinol Metab 2000;85:3779-85.

47 Thalassinos NC, Tsagarakis S, loannides G, et al. Megavoltage pituitary irradiation lowers but seldom leads to safe $\mathrm{GH}$ levels in acromegaly: a long-term follow-up study. Eur J Endocrinol 1998;138:160-3

48 Gutt B, Hatzack C, Morrison K, et al. Conventional pituitary irradiation is effective in normalising plasma IGF-1 in patients with acromegaly. Eur $J$ Endocrinol 2001;144:109-16.

49 Cozzi R, Barausse M, Asnaghi D, et al. Failure of radiotherapy in acromegaly. Eur J Endocrinol 2001;145:717-26.

50 Brada M, Ford D, Ashley S, et al. Risk of second brain tumour after conservative surgery and radiotherapy for pituitary adenoma. BM 1992; 304:1343-6.

51 Tsang RW, Laperriere NJ, Simpson WJ, et al. Glioma arising after radiation therapy for pituitary adenoma. A report of four patients and an estimation of risk. Cancer 1993;72:2227-33. 
52 Maire J P, Coudin B, Guerin J, et al. Neuropsychologic impairment in adults with brain tumours. Am J Clin Oncol 1987:10:156-62.

53 Brada M, Burchell L, Ashley S, et al. The incidence of cerebrovascular incidents in patients with pituitary adenoma. Int J Radiat Oncol Biol Phys incidents in patients

54 Jackson IMD, Noren G. Role of gamma knife radiosurgery in acromegaly. Pituitary 1999;2:71-7.

55 Zhang N, Pan L, Wang EM, et al. Radiosurgery for growth hormone-producing pituitary adenomas. J Neurosurg 2000;93/suppl 3):6-9.
56 Landolt A M, Haller D, Lomax N, et al. Stereotactic radiosurgery for recurrent surgically treated acromegaly: comparison with fractionated radiotherapy. J Neurosurg 1998;88:1002-8.

\section{ANSWERS}

Q1. (A) F, (B) F, (C) T, (D) T, (E) F. Q2. (A) T, (B) F, (C) T, (D)

F, (E) T. Q3. (A) T, (B) F, (C) T, (D) F, (E) F. Q4. (A) T, (B) F, (C)

T, (D) T, (E) T. Q5. (A) T, (B) F, (C) F, (D) T, (E) F.

\section{Clinical Evidence-Call for contributors}

Clinical Evidence is a regularly updated evidence based journal available worldwide both as a paper version and on the internet. Clinical Evidence needs to recruit a number of new contributors. Contributors are health care professionals or epidemiologists with experience in evidence based medicine and the ability to write in a concise and structured way.

Currently, we are interested in finding contributors with an interest in the following clinical areas:

Altitude sickness; Autism; Basal cell carcinoma; Breast feeding; Burns; Carbon monoxide poisoning; Cervical cancer; Chronic renal failure; Cystic fibrosis; Ectopic pregnancy; Emphysema; Grief/bereavement; Halitosis; Hodgkins disease; Infectious mononucleosis (glandular fever); Jet lag; Kidney stones; Malignant melanoma (metastatic); Mesothelioma; Myeloma; Ovarian cyst; Pancreatitis (acute); Pancreatitis (chronic); Polycystic ovaries; Polymyalgia rheumatica; Post-partum haemorrhage; Pulmonary embolism; Recurrent miscarriage; Repetitive strain injury; Scoliosis; Seasonal affective disorder; Squint; Systemic lupus erythematosus; Testicular cancer; Uterine prolapse; Varicocele; Viral meningitis; Vitiligo

However, we are always looking for others, so do not let this list discourage you.

Being a contributor involves:

- Appraising the results of literature searches (performed by our Information Specialists) to identify high quality evidence for inclusion in the journal.

- Writing to a highly structured template (about 2000-3000 words), using evidence from selected studies, within 6-8 weeks of receiving the literature search results.

- Working with Clinical Evidence Editors to ensure that the text meets rigorous epidemiological and style standards.

- Updating the text every eight months to incorporate new evidence.

- Expanding the topic to include new questions once every 12-18 months.

If you would like to become a contributor for Clinical Evidence or require more information about what this involves please send your contact details and a copy of your CV, clearly stating the clinical area you are interested in, to Claire Folkes (cfolkes@bmigroup.com).

\section{Call for peer reviewers}

Clinical Evidence also needs to recruit a number of new peer reviewers specifically with an interest in the clinical areas stated above, and also others related to general practice. Peer reviewers are health care professionals or epidemiologists with experience in evidence based medicine. As a peer reviewer you would be asked for your views on the clinical relevance, validity and accessibility of specific topics within the journal, and their usefulness to the intended audience (international generalists and health care professionals, possibly with limited statistical knowledge). Topics are usually 2000-3000 words in length and we would ask you to review between 2-5 topics per year. The peer review process takes place throughout the year, and our turnaround time for each review is ideally 10-14 days.

If you are interested in becoming a peer reviewer for Clinical Evidence, please complete the peer review questionnaire at www.clinicalevidence.com or contact Claire Folkes (cfolkes@bmigroup.com). 